\title{
Simulation of Hypertrophy in Rat Left Ventricular Cells
}

\author{
S Kharche ${ }^{1}$, H Zhang ${ }^{2}$, RC Clayton ${ }^{3}$, AV Holden ${ }^{1}$ \\ ${ }^{1}$ Computational Biology Laboratory, University of Leeds, Leeds, UK \\ ${ }^{2}$ Department of Physics, UMIST, Manchester, UK \\ ${ }^{3}$ Department of Computing, University of Sheffield, Sheffield, UK
}

\begin{abstract}
Left ventricular hypertrophy induces remodeling for various ion channels. We modified a model of electrical activity of rat ventricular cell by incorporating available experimental data on the kinetics and conductances of various currents. We simulated hypertrophy by incorporating experimental data of changes in channel kinetics, cell size and $\mathrm{Ca}^{2+}$ handling. The simulated action potentials (AP) and calcium transients consistent with experimental data. We developed virtual ventricular strands to investigate the rate dependent propagation in homogenous tissue under normal and hypertrophic conditions. A continuous increase in APD and corresponding decrease in conduction velocity $(C V)$ with subsequent beats was observed, resulting in irregular conduction block at low values of stimulus intervals (SI), for which the simulated action potential duration (APD) restitution of the cell models has negative slope.
\end{abstract}

\section{Introduction}

Cardiac muscle can respond to long term increase in demand placed upon it or advancement of age by cellular hypertrophy. Hypertrophy is a major cause of cardiac disease.

Hypertrophy induces an increased action potential duration (APD) and calcium transient duration. It reduces the calcium transient amplitude. The electrical restitution properties of cells often dictate spatial behaviours and their instabilities. The relationship between APD of successive pulses $\mathrm{APD}_{\mathrm{n}}$ and their corresponding diastolic intervals is given by

$$
\mathrm{APD}_{\mathrm{n}+1}=f\left(\mathrm{SI}-\mathrm{DI}_{\mathrm{n}}\right)
$$

where $f$ is the restitution relationship for single cell. It is known that if as $\left|d f / d \mathrm{DI}_{\mathrm{n}}\right|>1$ then the APD becomes unstable. The case for $d f / d \mathrm{DI}_{\mathrm{n}}>1$ leads to alternans instability. The case when $d f / d \mathrm{DI}_{\mathrm{n}}<-1$ leads to a new type of instability. Idealised models have been shown to exhibit a monotonically increasing APD rather than alternans behaviour when $d f / d \mathrm{DI}_{\mathrm{n}}<-1$ [1]. Moreover, we can expect intermittent conduction block in $1 \mathrm{D}$ virtual strand.

\section{Methods}

A computer model of rat left ventricular cell was constructed by modifying an already existing model [2]. The main modifications included were as following.

For the control or normal cell model, we incorporated experimental data on the kinetics and conductances of $\mathrm{L}$ type $\mathrm{Ca}^{2+}$ channel [3], transient outward current [4], and the $\mathrm{Na}^{+}$current [5]. The calcium handling mechanism was taken from [6].

To simulate hypertrophy [7], we incorporated data of hypertrophy induced down-regulation of transient outward current, up-regulation of $\mathrm{Na}^{+} / \mathrm{K}^{+}$pump current, up-regulation of $\mathrm{Na}^{+}$current, up-regulation of hyperpolarizing current [8], up-regulation of the $\mathrm{Na}^{+}-\mathrm{Ca}^{2+}$ exchanger current [9]. A $30 \%$ increase in cell capacitance [10], 30\% increase in cell size $[11,12]$ was also implemented. Hypertrophy induced T-type calcium current was also considered. Steady state kinetics were obtained from [13]. The time constants and formulation for the current were taken from [14]. Both control and hypertrophic models were integrated using a simple forward Euler method with a time step of $0.1 \mu$ s which gave stable solutions.

The virtual strand was $8 \mathrm{~mm}$ long. Electrotonic interaction between cells was simulated through diffusive coupling and 1D models were developed by incorporating single cell models into a parabolic partial differential equation (PDE) of the form

$$
C \frac{d V}{d t}=D \frac{\partial^{2} V}{\partial x^{2}}-I_{\text {ion }}
$$

where $I_{\text {ion }}$ is the total cellular ionic current, $V$ is the cell membrane voltage, $C$ is cell capacitance, and $D$ is the diffusion constant. The space step was $0.1 \mathrm{~mm}$. No flux boundary conditions were imposed at each end of the strand. Diffusion constant was set to a value of $0.1 \mathrm{~cm}^{2} / \mathrm{s}$. Periodic waves were stimulated in the strand by applying a periodic SI to 7 nodes situated at one end of the strand. Stimulus duration was $5 \mathrm{~ms}$. Strength of SI was $0.6 \mathrm{pA}$ in 
case of control strand, and $1.8 \mathrm{pA}$ in case of hypertrophic strand. A total of 10 stimuli were applied during each simulation. With the chosen value $\mathrm{D}$, we obtained a $\mathrm{CV}$ of $14.2 \mathrm{~cm} / \mathrm{s}$ in control strand [15]. The corresponding $\mathrm{CV}$ for hypertrophic strand was $9.2 \mathrm{~cm} / \mathrm{s}$.

In case of single cell models, we measure $\mathrm{APD}_{90}$ and calcium transient duration and amplitude. We measure single cell restitution from the final APD and DI. In case of the virtual strand simulations, we measure the APD and $\mathrm{CV}$ as a function of time and space. We repeat strand simulations for increasingly smaller SI, i.e. for higher pacing rates.

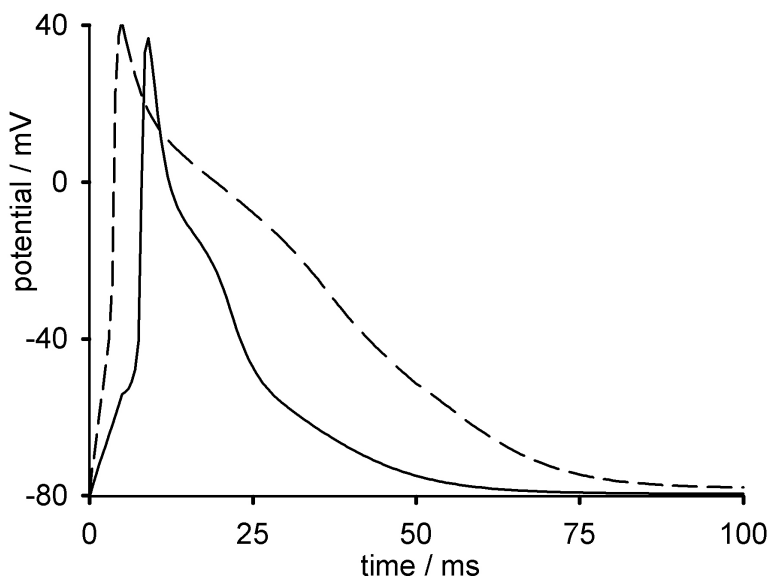

Figure 1: Solitary action potential profiles of single cell control and hypertrophic models. Solid line represents control and dashed line represents hypertrophic model.

\section{Results}

We incorporate all the modifications mentioned in the previous section and construct control and hypertrophic models. The resulting $\mathrm{APD}_{90}$ obtained is $41.5 \mathrm{~ms}$ for control and $73.2 \mathrm{~ms}$ for hypertrophy. There is a $77 \%$ increase in APD induced by hypertrophy. APD profiles are compared in Figure 1. Corresponding calcium transients are compared in Figure 2. A significant reduction in calcium transient amplitude from $276 \mathrm{nM}$ to $195 \mathrm{nM}$ is induced by hypertrophy, a change of $30 \%$. Input resistance is increased by $223 \%$. Table 1 lists computed changes.

Single cell dynamic APD restitution for control and hypertrophic models was obtained. A total of 10 stimuli were applied with progressively decreasing values of SI. At short SI we saw that the APD increased monotonically with time, with each successive stimulus. Final values of APD and DI were noted. Restitution curves were constructed by plotting $\mathrm{DI}_{\mathrm{n}}$ against $\mathrm{APD}_{\mathrm{n}+1}$. Figure 3 shows the restitution curves for control and hypertrophic models. For values of SI lower than $230 \mathrm{~ms}$ in control case and $450 \mathrm{~ms}$ in hypertrophy case we saw that APD increased monotonically. The APD restitution agrees qualitatively with experimental results [16].

\begin{tabular}{|l|l|l|}
\hline Quantity & Control Model & $\begin{array}{l}\text { Hypertrophic } \\
\text { Model }\end{array}$ \\
\hline $\mathrm{V}_{\text {rest }}$ & $-80.1 \mathrm{mV}$ & $-78.2 \mathrm{mV}$ \\
\hline $\mathrm{R}_{\text {in }}$ & $78 \mathrm{M} \Omega$ & $232 \mathrm{M} \Omega$ \\
\hline $\mathrm{dv} / \mathrm{dt}_{\mathrm{max}}$ & $132 \mathrm{~V} / \mathrm{s}$ & $90 \mathrm{~V} / \mathrm{s}$ \\
\hline Peak overshoot & $34.5 \mathrm{mV}$ & $37.08 \mathrm{mV}$ \\
\hline $\mathrm{APD}_{90}$ & $41.5 \mathrm{~ms}$ & $73.2 \mathrm{~ms}$ \\
\hline $\mathrm{Ca}_{\mathrm{i}, \text { rest }}$ & $78.54 \mathrm{nM}$ & $88.05 \mathrm{nM}$ \\
\hline $\mathrm{Ca}_{\mathrm{i}, \text { peak }}$ & $355.02 \mathrm{nM}$ & $283 \mathrm{nM}$ \\
\hline $\mathrm{SR}_{\text {rest }}$ & $65.86 \mu \mathrm{M}$ & $65.96 \mu \mathrm{M}$ \\
\hline $\mathrm{Q}_{\mathrm{NaCa}}$ & $24.18 \mathrm{pC}$ & $144 \mathrm{pC}$ \\
\hline $\mathrm{Q}_{\mathrm{bCa}}$ & $4.7 \mathrm{pC}$ & $4.64 \mathrm{pC}$ \\
\hline $\mathrm{Q}_{\text {Ical }}$ & $14.99 \mathrm{pC}$ & $13.12 \mathrm{pC}$ \\
\hline & &
\end{tabular}

Table 1: Numerical quantities as measured in the control and hypertrophic cell models. Symbols used are the same as in [2].

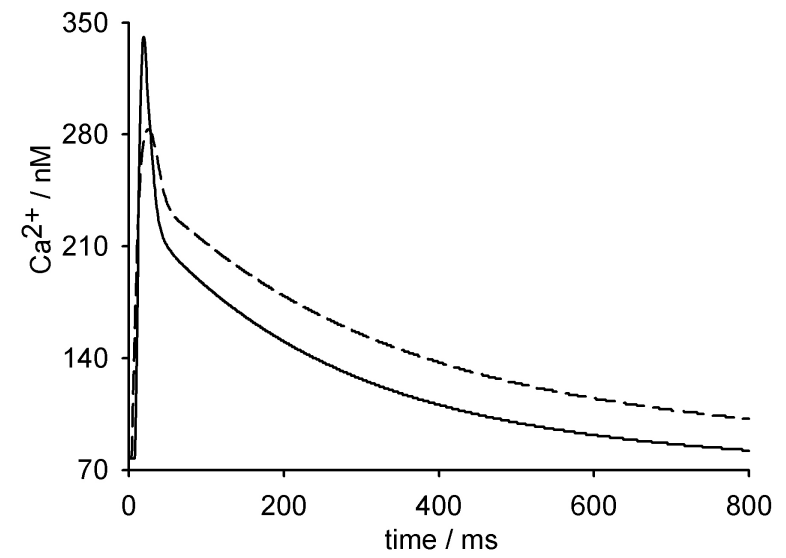

Figure 2: Calcium transients in control (solid line) and hypertrophic models (dashed line). The amplitude in hypertrophic case reduced considerably and the duration increases.

We simulated virtual tissue strands with values of SI taken were between $200 \mathrm{~ms}$ and $1000 \mathrm{~ms}$. For values of SI more than $500 \mathrm{~ms}$, both models gave stable propagation. At a SI of $500 \mathrm{~ms}$, the hypertrophic model demonstrated a marked increase in APD as a function of successive stimuli. This is shown in Figure 4. A similar increase in APD as a function of time is observed for the control model at approximately SI $=230 \mathrm{~ms}$. This increase in APD influences $\mathrm{CV}$, especially close to the stimulation site. Taking the hypertrophic case with SI = $500 \mathrm{~ms}$, we observe that $\mathrm{CV}$ reduces considerably at successive stimuli. We show this in Figure 5. As a 


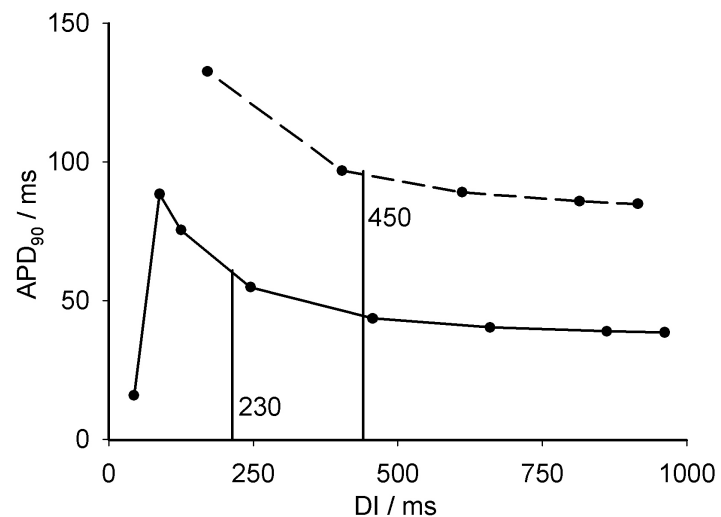

Figure 3: Single cell dynamic restitution for control (solid line) and hypertrophic (dashed line) models. Slope of control restitution curve becomes steeper than -1 at SI intervals of $230 \mathrm{~ms}$ in control case. Corresponding value in hypertrophic case is $450 \mathrm{~ms}$.

function of space, the further we are from the stimulation patch, the values of $\mathrm{CV}$ are closer. We can thus see that

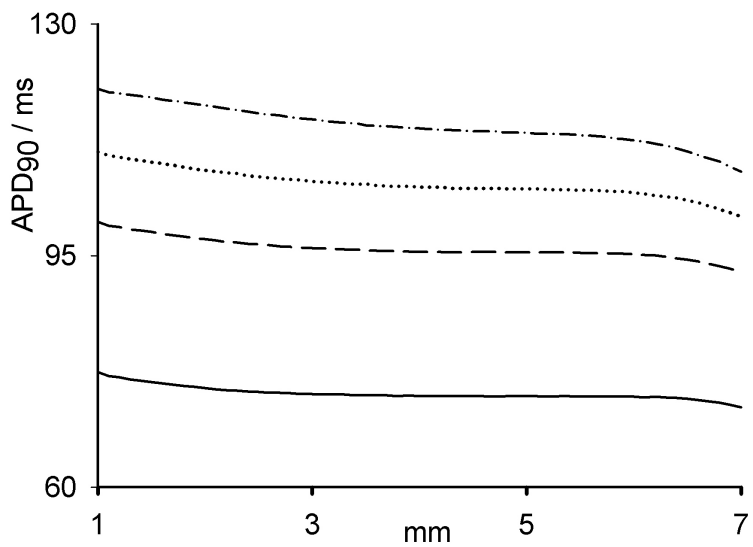

Figure 4: Spatio-temporal variation of APD in hypertrophic model at SI $=500 \mathrm{~ms}$. Solid line represents APD at $1^{\text {st }}$ stimulus, dashed line at $4^{\text {th }}$ stimulus, dotted line at $7^{\text {th }}$ stimulus, and dashed-dotted line at $10^{\text {th }}$ stimulus. The differences in APD reduce as the respective waves propagate through the homogenous medium. A similar phenomenon is observed in the control case, albeit at a much lower SI of $230 \mathrm{~ms}$. The APDs are shorter and lie in a range of 20 to $100 \mathrm{~ms}$.

on a beat to beat basis the APD increases, and the corresponding $\mathrm{CV}$ reduces monotonically. We search for instability in the negatively sloped region of the cell restitutions. If we search for $\mathrm{CV}$ becoming zero or close to zero at or before application of $10^{\text {th }}$ stimulus, this is a sufficient test for blocking of a beat. This would be by intermittent conduction block, produced by dynamic

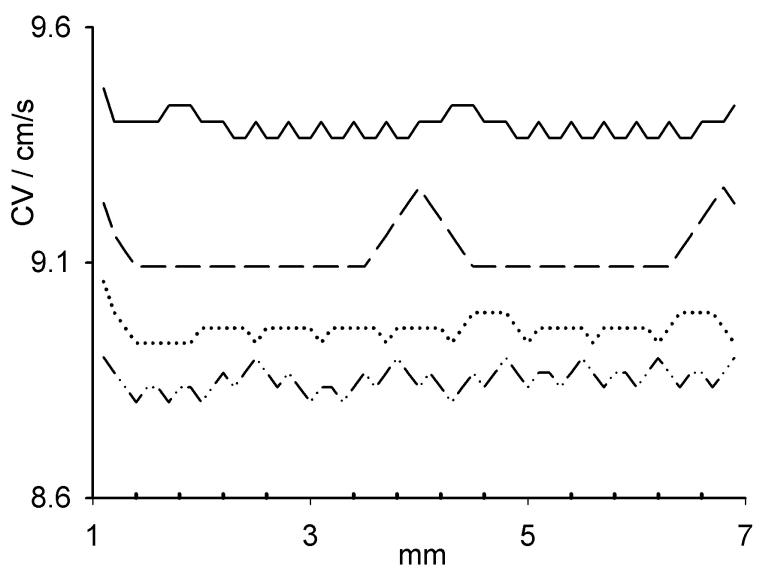

Figure 5: Spatio-temporal variation of $\mathrm{CV}$ in hypertrophic model at $\mathrm{SI}=500 \mathrm{~ms}$. Solid line represents $\mathrm{CV}$ at $1^{\text {st }}$ stimulus, dashed line at $4^{\text {th }}$ stimulus, dotted line at $7^{\text {th }}$ stimulus, and dashed-dotted line at $10^{\text {th }}$ stimulus. A similar phenomenon is observed in the control case, albeit at a much lower SI of $230 \mathrm{~ms}$. The CVs are larger and lie in a range of $9 \mathrm{~cm} / \mathrm{s}$ to $15 \mathrm{~cm} / \mathrm{s}$.

heterogeneity in our parametrically homogenous models. Blocks of this type occur when restitution curves become steeper than -1. Value of SI for control model is $220 \mathrm{~ms}$. The corresponding value for hypertrophic model is 400 ms.

\section{Discussion and conclusions}

Single cell models of left ventricular tissue for normal and hypertrophic cells were successfully constructed. We further incorporated these into one-dimensional virtual strands and studied the effects of fast pacing. A peculiar property of these models is the existence of a negative slope region in their single cell restitutions. This results in a monotonic change in APD and CV in the 1D tissue models. Alternans behaviour, as in case of a positive sloped restitution, is not observed.

\section{Acknowledgements}

This research was supported by Medical Research Council (UK) and British Heart Foundation (UK) grants.

\section{References}

[1] Panfilov AV, Zemlin CW. Wave propagation in an excitable medium with a negatively sloped restitution curve. Chaos 2002; 12(3): 800-806.

[2] Pandit SV, Clark RB, Giles WY, Demir SS. A mathematical model of action potential heterogeneity in adult rat ventricular myocytes. Biophysical Journal 2001; 81: 3029-3051.

[3] Linz KW, Meyer R. Profile and kinetics of L-type calcium current during the cardiac ventricular action potential 
compared in guinea-pigs, rats and rabbits. Pflugers Arch Eur J Physiol. 2000; 439: 588-599.

[4] Li Q and Keung EC. Effects of myocardial hypertrophy on transient outward current. Am. J. Physiol. 1994; 266: H1738-H1745.

[5] Zhang H, Holden AV, Kodama I, Honjo H, Lei M. Mathematical models of action potentials in the periphery of and centre of the rabbit sinoatrial node. Am. J. Physiol. 2000; 279: H397-H421.

[6] Winslow RL, Rice J, Jafri S, Marban E, O'Rourke B. Mechanisms of altered excitation-contraction coupling in canine tachycardia-induced heart failure II. Model studies. Circ. Res. 1999; 84: 571-586.

[7] Padmala S, Demir SS. Computational Model of the Ventricular Action Potential in Adult Spontaneously Hypertensive rats. Journal of Cardiovasc. Electrophysiol. 2003; 14(9): 990.

[8] Fernandez-Velasco M, Goren N, Benito G, Blanco-Rivero J, Bosca L, Delgado C. Regional distribution of hyperpolarization-activated current (If) and hyperpolarization-activated cyclic nucleotide-gated channel mRNA expression in ventricular cells from control and hypertrophied rat hearts. J Physiol (Lond) 2003; 553: 395405.

[9] Gomez A M, Schwaller B, Porzig H, Vassort G,Niggli E, Eger M. Increased Exchange Current but Normal Ca2+ Transport via INaCa exchange during cardiac hypertrophy after myocardial infraction. Circ. Res 2002; 91: 323-330.

[10] Yokoshiki H, Kohya T, Tomita F, Tohse N, Nakaya N, Kanno M, Kitabatake A. Restoration of action potential duration and transient outward current by regression of left ventricular hypertrophy. J Mol. Cell Cardiol. 1997; 29:
1331-1339.

[11] Qin D, Zhang Z, Caref E B, Boutjdir M, Jain P, El-Sherif N. Cellular and Ionic Basis of Arrhythmias in Postinfarction Remodeled Ventricular Myocardium. Circ. Res. 1996; 79(3): 461-473.

[12] Gomez, A M, Benitah, J P, Henzel D, Vinet A, Lorente P, Delgado C. Modulation of electrical heterogeneity by compensated hypertrophy in rat left ventricle. Am. J. Physiol. 1997; 272(3): H1078-1086.

[13] Izumi T, Kihara Y, Sarai N, Yoneda T, Iwanaga Y, Inagaki. Reinduction of T-Type Calcium Channels by Endothelin-1 in Failing Hearts In Vivo and in Adult Rat Ventricular Cells. Circulation 2003; 108(20): 2530-2535.

[14] Dokos S, Celler B, Lovell N. Vagal Control of Sinoatrial Rhythm: a Mathematical Model. Journal of Theoretical Biology. 1996; 182(1): 21-44.

[15] Meiry G, Reisner Y, Feld Y, Goldberg S, Rosen M, Ziv N, Binah O. Evolution of action potential propagation and repolarization in cultured neonatal rat ventricular myocytes. J Cardiovasc. Electrophysiol. 2001; 12(11): 1269-77.

[16] Nanasi PP, Pankucsi C, Banyasz T, Szigligeti P, Papp JG, Varro A. Electrical restitution in rat ventricular muscle. Acta Physiol Scand. 1996; 158(2): 143-53.

Address for correspondence

Name: Sanjay Kharche

Full postal address: Biomedical Sciences, University of Leeds, Leeds LS2 9JT, UK

E-mail address: S.Kharche@leeds.ac.uk 